\title{
Símbolo e intelecto en la filosofía de Jámblico: en torno a De Mysteriis 2.11.20-41
}

\section{Symbol and intellect in the philosophy of Iamblichus: regarding De Mysteriis 2.11.20-41}

\author{
María Jesús Hermoso FÉLiX \\ (Universidad de Valladolid)
}

Recibido: 06/11/2013

Aceptado: 27/02/2014

\section{Resumen}

En el presente artículo abordamos la cuestión de la naturaleza del símbolo en la filosofía de Jámblico a través del análisis del pasaje de De Mysteriis 2.11.20-41. Este pasaje ha servido de apoyo a la exégesis que ve en el símbolo un elemento apartado del intelecto. Según esta lectura, el símbolo habría sido introducido por Jámblico para salvar la debilidad del alma humana ante lo divino. Éste habría dejado de confiar en las capacidades del hombre, abriéndose al ámbito de la teúrgia. Éste marco de interpretación adolece, sin embargo, de importantes carencias a la hora de ofrecer una comprensión profunda y coherente del papel del símbolo en la filosofía de Jámblico. A partir del estudio de este pasaje, nos acercaremos a la naturaleza de lo simbólico, buscando abrir una vía de comprensión de su papel en el proceso epistémico que perfila Jámblico. La relación que guarda esta noción con el término voє९óৎ será determinante para nuestro estudio.

Palabras clave: Jámblico, símbolo, conocimiento, intelecto, Neoplatonismo.

\begin{abstract}
In this article we discuss the question of the nature of the symbol in the philosophy of Iamblichus by analyzing the text of De Mysteriis 2.11.20-41. This text has supported exegesis that sees the symbol as something out of the intellect. According to this interpretation, the symbol would have been introduced by Iamblichus to save the weakness of the human soul in relation to the divine, opening the field of theurgy. This framework of interpretation suffers, however, significant shortcomings in
\end{abstract}


providing a deep understanding of the role of the symbol in the philosophy of Iamblichus. From the study of the text of De Mysteriis 2.11.20-41, we will approach the symbolic nature, seeking to establish a way of understanding its role in the epistemic process. The relationship of this notion with the term voepós will be crucial for our study.

Keywords: Iamblichus, symbol, knowledge, intellect, Neoplatonism.

\section{Introducción}

Jámblico es uno de los primeros filósofos que abre la cuestión de lo simbólico a la reflexión filosófica, planteándose el carácter epistémico del símbolo. En el De Mysteriis encontramos la fuente de muchas de las reflexiones que se llevarán a cabo sobre esta cuestión en la filosofía posterior. Podemos decir con Charles-Saget que: «Jamblique est le premier philosophe qui ait ouvert à l'ensemble des symboles l'espace de la réflexion philosophique. Ce sont l'anthropologie, la psychanalyse et 1'histoire des religions qui en ont à notre époque repris l'étude» ${ }^{1}$. Sin embargo, la función epistémica del símbolo en el pensamiento de Jámblico, su papel en la teoría del conocimiento, es una de las cuestiones más difíciles de abordar y, en la mayoría de los casos, más incomprendidas. Mucho nos jugamos en su dilucidación, precisamente porque ésta nos acercaría importantes claves de comprensión acerca de la cualidad de lo simbólico en la filosofía posterior.

La naturaleza del símbolo en la filosofía de Jámblico ha venido a concebirse, en la obra de una gran mayoría de estudiosos, desde la planta general de interpretación de su pensamiento que instaurara Dodds. Éste considera el De Mysteriis en su conjunto como un manifiesto del irracionalismo ${ }^{2}$. Jámblico habría dejado de confiar en la capacidad del intelecto para llegar a la unión a lo divino, inaugurando una nueva vía: la teúrgia, con sus rituales y sus símbolos. El De Mysteriis habría abandonado la vía intelectual que sirviera a Plotino en su camino hacia lo divino. El símbolo quedaría, así, considerado como un elemento irracional que busca la unión del alma a lo divino a través de un ámbito alejado del intelecto. Esta interpretación introduce una brecha entre Plotino y Jámblico que demarca un antes y un después en la historia del Neoplatonismo, dejando incomprendido el valor epistémico del símbolo.

\footnotetext{
1 «La théurgie, nouvelle figure de l'ergon dans la vie philosophique», en The divine Iamblichus, Bristol, 1993, p.113.

2 Cf. Dodds E. R. The greeks and the irracional, Berkeley: Univ. of California Press, 1973 (Trad. española de Araujo M.: Los griegos y lo irracional, Madrid: Alianza, 1981, p. 270). Sobre esta cuestión cf. Hermoso Félix M.J. "Saber y razón en el Neoplatonismo: hacia una nueva comprensión de la filosofía de Jámblico", en Anales del Seminario de historia de la Filosofía, Vol. 29, n¹, 2012, pp. 27-44.
} 
Es importante repensar y reflexionar sobre la validez de este marco que puede estar dejando elementos importantes en la sombra. En los últimos tiempos cada vez más estudiosos procuran indagar en el pensamiento de Jámblico, poniendo en cuestión los antiguos moldes y buscando una mayor valoración de su filosofía ${ }^{3}$. En el presente artículo nos sumamos a esta línea focalizando nuestra atención en un punto: la reflexión sobre naturaleza intelectual del símbolo en el De Mysteriis de Jámblico.

Con el fin de llevar a cabo una reflexión calmada sobre la naturaleza intelectual del símbolo y sobre su papel en el proceso epistémico, atenderemos a los lugares del De Mysteriis en los que se apoya la lectura que ve en el símbolo un elemento irracional, sobrenatural, que se propone como vía alternativa al intelecto. Veremos cómo esta lectura da un valor central a determinados pasajes, dejando otros de lado. Los que se toman como referencia se leen desde un marco que otorga significados cerrados a los términos que se encuentran en ellos; de tal modo que la tesis de partida se ve validada en esta atribución. Este marco, por lo demás, no da cuenta de la complejidad en el significado de los términos y genera problemas a la hora de desplegar una hermenéutica conjunta e integrada de los textos. Como mostraremos más adelante, diferentes pasajes del De Mysteriis vendrían a contradecirse entre sí en lo referente a la comprensión del símbolo.

\section{De Mysteriis 2.11.20-41: Un texto polémico}

Comenzamos citando el pasaje que se aduce para poner de relieve el carácter no intelectual del símbolo, De Mysteriis 2.11.20-41. Este texto vendría a ejemplificar el proceso de introducción de la filosofía Neoplatónica en el ámbito de lo irracional a partir de Jámblico:

[...] La unión teúrgica es infundida por la eficacia de aquellas obras que son inefables y que, por encima de toda intelección, son llevadas a cabo como corresponde a lo divino, así como por el poder de los símbolos silenciosos, comprendidos por los dioses solamente. Por ello, tampoco los llevamos a cabo con el pensar, pues, en tal caso, su actividad sería intelectual y producto nuestro. Pero ni lo uno ni lo otro es verdad. En efecto, incluso sin que nosotros pensemos los símbolos mismos cumplen su función propia por sí mismos, y el inefable poder de los dioses, hacia los que estos símbolos se elevan, reconoce sus propias imágenes él mismo por sí mismo y no porque sea despertado

\footnotetext{
${ }^{3}$ La obra de Dalsgaard L.B. Jamblique de Chalcis, exégète et philosophe, Aarhus: Universitetforlaget, 1972, abre un intento continuado de recuperación del pensamiento de Jámblico; en esta línea encontramos estudiosos como Van Liefferinge C. La Thèurgie : Des Oracles Chäldaiques à Proclus, Liège : Kernos, 1999; Clarke E. C. Iamblichus' De Mysteriis: A manifiesto of the miraculous, Aldershot: Alsgate, 2001; o Uzdavinys A. Philosophy and Theurgy in Late Antiquity, USA: Sophia Perennis, 2010.
} 
por nuestro pensamiento. Pues no es natural que lo que abraza sea puesto en movimiento por lo abrazado, ni lo perfecto por lo imperfecto ni el todo por las partes. De ahí, que tampoco las causas divinas sean llamadas al acto por una acción previa de nuestros pensamientos: y si bien éstos, junto con todas las mejores disposiciones del alma y nuestra pureza, tienen que darse con anterioridad como causas en alguna medida coadyuvantes, sin embargo lo que propiamente despierta la voluntad divina son los símbolos divinos mismos. De modo que lo divino se pone en movimiento ello mismo por sí mismo, sin recibir de los seres inferiores ningún principio de su acto propio 4 .

Reproducimos la traducción de las primeras líneas del texto que lleva a cabo Pierre Hadot, uno de los grandes estudiosos del Neoplatonismo, al que debemos una importante parte de los estudios y traducciones actuales de Plotino: "L'acomplissement des opérations ineffables qui dépassent toute connaissance, selon un mode qui convient aux dieux, et la puissance des symboles indecibles compris par les dieux seuls produisent l'union théurgique. Ainsi n'est-ce point par l'intelligence que nous accomplissons les choses sacrées : sinon cette opération sera un effet de notre intelligence y dépendra de nous". Tras citar el texto añade que: "Ce texte de Jamblique montre bien le supernaturalisme qui a envahi le platonisme tardif et qui sépare si profondément Jamblique de Plotin et de Porphyre"5.

Este texto es, asimismo, citado por H. D. Saffrey, otro importante y prolífico estudioso del Neoplatonismo, añadiendo la siguiente interpretación: “Ce qui veut dire que pour Jamblique, l'union a la divinité est un rite ineffable où opèrent non pas les forces de notre esprit, mais l'action des dieux déclenchée par la manipulation des symboles"6. También Luc Brisson, reconocido especialista en los estudios neoplatónicos, al que debemos una magnífica traducción de la Vida Pitagórica de Jámblico, cita este texto, al que hace el siguiente comentario: "La vérité ne peut être atteinte qu'au terme d'une révélation que dispensent les dieux eux-mêmes qui

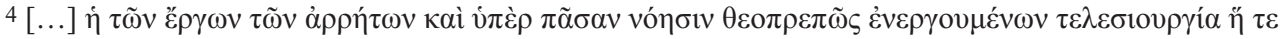

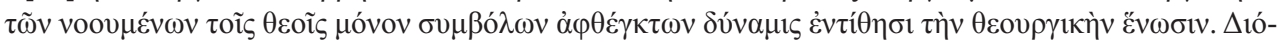

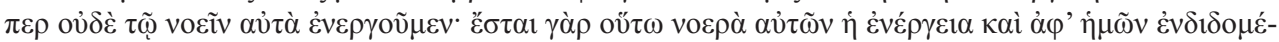

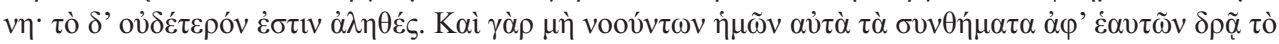

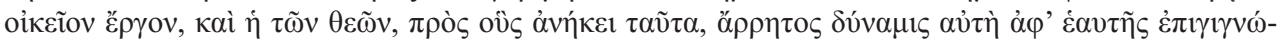

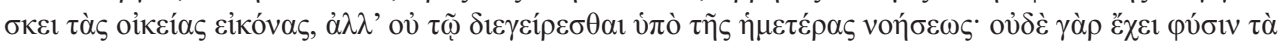

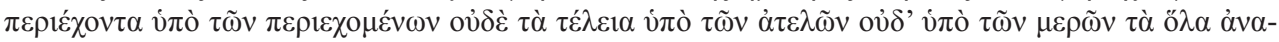

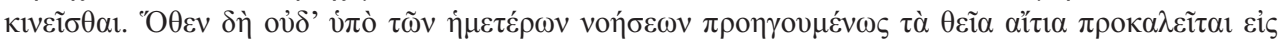

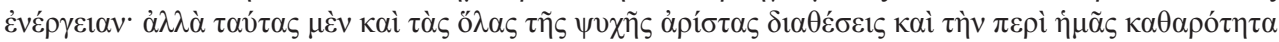

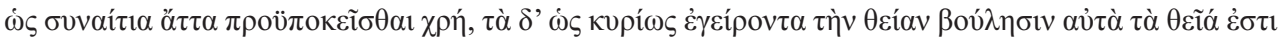

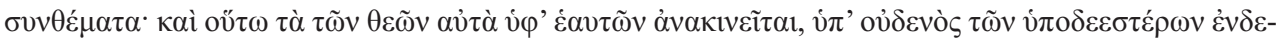

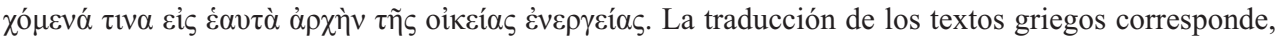
con alguna variación, a la versión castellana referida, en cada caso, en la bibliografía.

${ }^{5}$ Hadot P., en la obra de Lewy H. Chaldean Oracles and theurgy. París, 1978, p. 717.

6 Saffrey H. D. La théurgie chez les néoplatoniciens, en Recherches sur le Néoplatonisme après Plotin. París, 1990, p. 168.
} 
apportent ainsi un remède à la faiblesse humaine"7.

Estas hermenéuticas tienden a dar por sentado, como ya lo hiciera Dodds, el carácter irracional del símbolo, carácter que vendría a introducir una novedad en el pensamiento de raigambre platónica. El hombre deja de confiar en la potencia del intelecto, abandonándose a mediaciones de corte irracional que puedan llegar a salvar la impotencia del alma ante lo divino ${ }^{8}$.

Tales interpretaciones presentan problemas a diversos niveles; el primero, y más importante, es la distorsión en torno a la comprensión del símbolo que introducen; el segundo viene referido a la propia congruencia del De Mysteriis en su conjunto. En relación al primer aspecto, el símbolo pierde su lugar en la teoría del conocimiento que propone Jámblico. La comprensión del lugar de lo simbólico en el proceso epistémico, el hondo calado de su propuesta, queda en la sombra. Las vinculaciones con la comprensión del conocimiento que plantea Plotino se pierden, emergiendo únicamente una contraposición roma y sin matices. En cuanto al segundo aspecto, estas interpretaciones no dejan cabida a una lectura integrada de los textos, planteando problemas de incompatibilidad entre ellos. Tal es el caso de la comprensión conjunta del texto citado (De Mysteriis 2.11.20) donde supuestamente se mostraría el carácter no intelectual del símbolo y De Mysteriis 7.4.1 donde se afirma expresamente que los nombres divinos, en su carácter simbólico, tienen un modo de

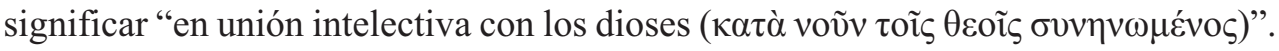
Añadiendo que: "lo que hay que retener en los nombres es precisamente aquella huella intelectual y divina, que constituye un símbolo de la semejanza divina

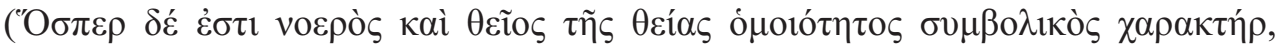

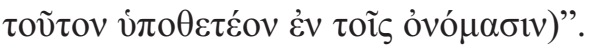

La interpretación de los textos desemboca en una comprensión concreta de la naturaleza del símbolo. No es poco lo que se juega en su lectura; por ello, proponemos dejar entre paréntesis las teorías acerca de la condición irracional del símbolo y atender a los textos desde sí mismos. Proponemos ahondar en el sentido interno de las afirmaciones acerca de la condición intelectual del símbolo que se llevan a cabo en ellos a través de un estudio semántico-estructural del léxico referido a lo

7 Brisson L. Orphée, Pythagore et Platon. Le mythe qui établit cette lignée, en Metaphysic und Religion. Leipzig, 2002, p. 423.

8 Tal como expresará Saffrey (op. cit. p. 164): "Renonçant à l'effort de la raison, on souhaite donc sortir de la nuit de l'esprit par un enseignement venu de l'Au-delà et auquel il n'y a plus qu'à ajouter foi". Súbitamente un gran pesimismo y una gran impotencia habrían venido a apoderarse de aquél espíritu griego que confiaba en sus propias fuerzas como único bagaje en su comprensión de lo real. Tal vez esta cartografía de la mutación del espíritu griego sea deudora de hermenéuticas posteriores que han querido ver en él el precursor del pensamiento ilustrado contra las potencias irracionales del mito. Tal vez ni el espíritu griego fue nunca tan autosuficiente ni llegó a ser nunca tan pesimista e impotente. En este punto se hace necesaria una nueva perspectiva que arroje una nueva luz al sentido interno de los textos del platonismo para llegar a comprender la coherencia profunda que anima a la filosofía neoplatónica de este periodo. 
intelectivo ${ }^{9}$. A partir del mismo, intentaremos desplegar una hermenéutica que abrace el sentido conjunto de las diferentes afirmaciones, que se muestran, en un primer momento, como aparentemente contradictorias.

De esta manera, daremos prioridad, de un lado, al estudio detenido de los textos, de otro, a ensayar una hermenéutica que muestre su sentido interno como un sentido coherente que los abraza en su integridad, mostrando la compatibilidad de las diferentes afirmaciones que se encuentran en ellos. Este estudio ha de llevarnos a poner de manifiesto la complejidad semántica del léxico referido a lo intelectivo. Esta complejidad, en el pensamiento de Jámblico, busca responder a la complejidad misma de lo real y del alma, a su carácter dinámico. Los diferentes niveles epistémicos acompañarán a los diferentes niveles ontológicos, enhebrándose en una estructura compleja, articulada internamente de un modo fluido que escapa a una delimitación que pudiera ser objetivable de modo unívoco. Esta condición dinámica de las nociones centrales de la filosofía de Jámblico exige de una exégesis que sea capaz de sintonizar con ella, dando cuenta de su sentido interno más allá de proyecciones semánticas rígidas. De esta manera, analizaremos la estructura semántica en la que se engarzan los términos y de la que extraen su sentido propio. A través de este estudio iremos profundizando en la naturaleza del símbolo y en su cualidad intelectiva, que no se deja apresar en las categorías que lo definen como un elemento irracional que viniera a salvar la impotencia y la desconfianza en las fuerzas propias del alma humana ${ }^{10}$.

Llevaremos a cabo esta tarea estudiando de cerca el pasaje de De Mysteriis 2.11.20 al que nos hemos referido más arriba, investigando el sentido del léxico referido a lo intelectivo, de cara a profundizar en la naturaleza del símbolo. En esta labor nos será necesario recurrir a De Mysteriis 7.4.4-27, para realizar una lectura comparada de los dos pasajes. De este modo, podremos delimitar la comprensión del símbolo que se deriva de esta lectura conjunta.

El pasaje de De Mysteriis 2.11.20 guarda una complejidad extrema, quedando reflejadas en él muchas de las ideas que constituyen el eje del pensamiento de Jámblico. Prácticamente cada término ha de ser discutido, así como ha de compa-

\footnotetext{
9 Respecto a la naturaleza y la importancia de tener en cuenta este aspecto en el estudio de los textos cf. el lúcido estudio de Calvo Martínez T., "Léxico y filosofía en los presocráticos", en Logos. Anales del Seminario de Metafisica, 1971, p. 7, allí afirma que: "El estudio estructural del léxico abre una vía objetiva de acceso a cualquier filosofía".

10 Una hermenéutica atenta a los textos y a su lectura conjunta ha de mostrarnos que la distancia que se quiere ver entre Jámblico y el Neoplatonismo anterior no es tal. El nervio propio de esta filosofía no ha de buscarse en su carácter irracional, ni en un supuesto pesimismo que se entregara a las fuerzas irracionales de la religión. Bien al contrario, tal nervio propio, que marcará la escuela de Atenas, ha de verse en el ingente esfuerzo intelectual que lleva a cabo por intentar articular y dar una coherencia interna a los rituales del mundo pagano desde la filosofía neoplatónica, en un desesperado intento por salvar la vigencia de un mundo, que estaba siendo amenazado por el imparable ascenso del cristianismo.
} 
rarse su contexto semántico-estructural con el que figura en otros lugares de la obra. De lo contrario, se corre el riesgo de aislar determinadas nociones, proyectando sobre ellas significados que no les corresponden. Con ello, no alcanzaríamos el corazón del sentido de las afirmaciones que se hacen en las líneas que trataremos a continuación, tendiendo, en este mismo movimiento, a proyectar semánticas no acertadas no sólo sobre este texto sino sobre el conjunto del pensamiento de Jámblico.

En un primer momento, centraremos nuestra atención en una afirmación que contiene una expresión paradójica, en cuya resolución habremos de buscar una clave hermenéutica importante para dilucidar el sentido del resto del texto. A partir de ella, se irá desplegando nuestra argumentación, tratando de dar cuenta de una exégesis del texto compatible con la globalidad de la filosofía de Jámblico.

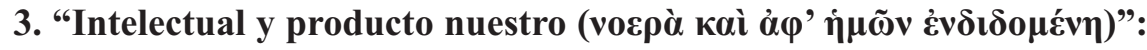 acerca de una afirmación paradójica}

La afirmación de la que partirá nuestro análisis se encuentra expresada en el contexto de las siguientes líneas del pasaje de De Mysteriis que venimos de citar:

La unión teúrgica es infundida por la eficacia de aquellas obras que son inefables y que, por encima de toda intelección, son llevadas a cabo como corresponde a lo divino, así como por el poder de los símbolos silenciosos, comprendidos por los dioses solamente. Por ello, tampoco los llevamos a cabo con el pensar, pues, en tal caso, su actividad sería

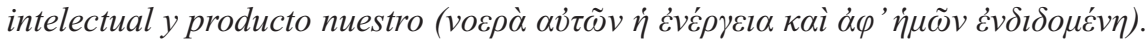

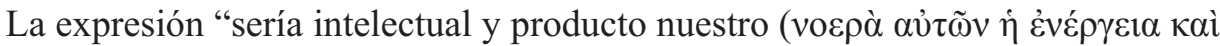

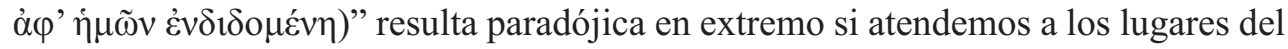
De Mysteriis y del conjunto de la obra de Jámblico donde es utilizado el término voepós y otros términos de su mismo campo semántico. Estos términos, en la mayoría de las ocasiones, aparecen asociados a lo divino, así como al elemento mismo que une al hombre con los dioses. El hombre, accediendo a la capacidad intelectiva del alma, accede al vínculo que le une a lo divino y le libera de la fatalidad11. Tal modo de conocimiento, que se cumple en orden a la semejanza y que se da sin oposición, constituye la mediación misma que conduce al hombre al modo de conocer de los dioses. En este sentido, leíamos en el De Mysteriis 1.3.35-40:

El alma humana únase a ellos, según los mismos principios, por el conocimiento, sin perseguir, en modo alguno, por representación, opinión o silogismo, que tienen su ori-

11 Cf. Myst. 8.6.11 ss. 
gen en el tiempo, la esencia superior a todos estos modos $<$ de conocimiento $>$, sino que

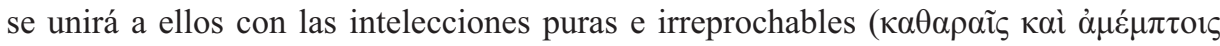

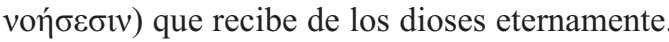

En consonancia con el resto de la obra, este texto, presenta el conocimiento intelectual como un elemento de mediación que el alma recibe eternamente de lo divino. Este modo de conocimiento, más allá tiempo y la oposición, trasciende los modos de conocimiento que Jámblico asocia a lo humano, aquellos que propiamente se presentan como "producto nuestro": la representación, la opinión y el silogis-

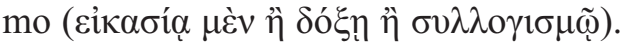

El conocimiento intelectual tiene la potencia de conducir al alma a grados crecientes de unidad, hasta desembocar en la unión a lo divino. En ningún caso, pues, podría concebirse que lo que compete a lo intelectual, en el sentido ahora expresado, fuese "producto nuestro". Antes bien, trasciende y eleva nuestros modos propios de conocer, perfeccionando la capacidad cognoscitiva del alma.

De otro lado, la concepción según la cual lo causado no puede, en modo alguno, constituir la fuente y raíz de la causa recorre la totalidad de la filosofía de Jámblico. La dirección de la causación es la inversa, de tal manera que la causa constituye la fuente y la raíz de lo causado, estando presente en el modo trascendente que le es propio. Lo intelectual, en tanto que principio de causación ${ }^{12}$ no puede, en modo alguno, ser "producto nuestro".

La condición paradójica de la afirmación que encontramos en el pasaje de De Mysteriis 2.11.20 que ahora tratamos ${ }^{13}$, nos conduce a una mayor perplejidad si la comparamos con la afirmación que se llevaba a cabo en De Mysteriis 7.4.11-27 sobre el modo de significar del nombre divino en su carácter simbólico. Éste se caracterizaba como un modo de significar "en unión intelectiva con los dioses ( $\kappa \alpha \tau \grave{\alpha}$

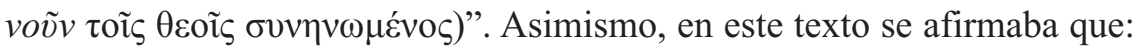

Lo que hay que retener en los nombres es precisamente aquella huella, intelectual y divi-

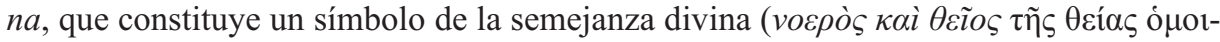

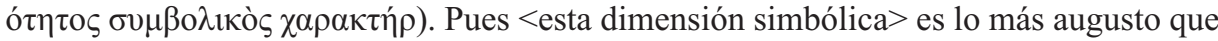

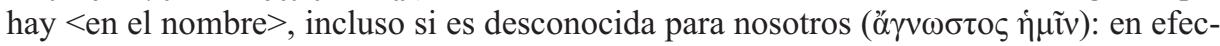
to, es demasiado elevada como para ser descompuesta con vistas a su conocimiento

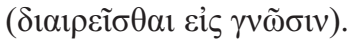

\footnotetext{
12 A este respecto, cf. Myst. 5.10.60: "El alma es perfeccionada por el intelecto, la naturaleza por el

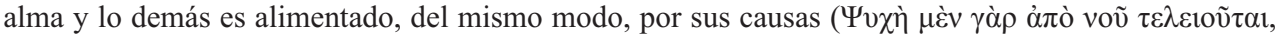

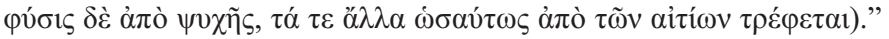

13 Esto es, que las obras inefables y los símbolos silenciosos no los llevamos a cabo con el pensar, pues

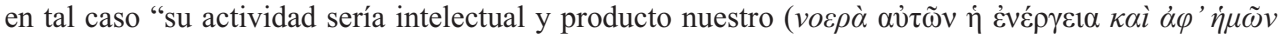
$\dot{\varepsilon} v \delta 1 \delta \circ \mu \varepsilon \dot{v \eta}) "$
} 
La propiedad simbólica del nombre divino queda ligada, en este pasaje, al ámbito intelectivo. La huella intelectual que hemos de retener en el nombre tiene un carácter divino: procede de lo divino y conduce a la semejanza divina. También en este pasaje de De Mysteriis se opone este conocimiento, propiamente intelectivo, con el modo de conocimiento asociado a nosotros: "todas las cavilaciones y expli-

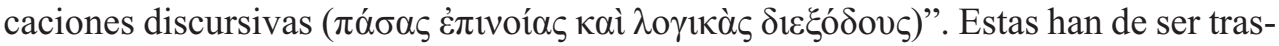
cendidas en el modo de saber que porta la naturaleza simbólica del nombre divino. Esta naturaleza simbólica se despliega en orden al nivel intelectivo, en tanto que abre al alma a un saber que se cumple en grados crecientes de semejanza hasta arribar, en última instancia, a su culminación en la unión a lo divino.

Desde esta compresión de lo simbólico, que atraviesa por completo la obra de Jámblico, no deja de sorprendernos la afirmación que se lleva a cabo en $D e$ Mysteriis 2.11.20 referida a las obras inefables y a los símbolos silenciosos: "tampoco los llevamos a cabo con el pensar, pues, en tal caso, su actividad sería intelec-

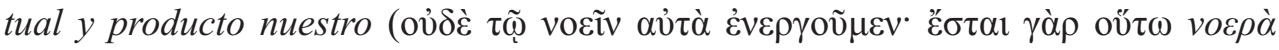

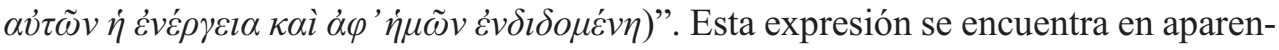
te contradicción con la que venimos de leer en De Mysteriis 7.4.11 referida a la naturaleza simbólica de los nombres divinos: "Lo que hay que retener en los nombres es precisamente aquella huella, intelectual y divina, que constituye un símbolo de la

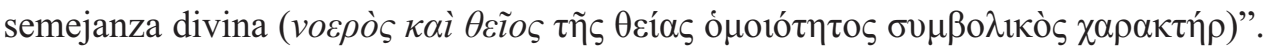

\section{La complejidad semántica del léxico referido a lo intelectivo}

Hemos de atender a otros textos para hallar una clave de comprensión que salve la aparente contradicción a la que venimos de referirnos en el epígrafe anterior. Ésta aparente contradicción apunta, como veremos, en última instancia, a la complejidad semántica del léxico referido a lo intelectivo. Ésta se cumple, de facto, en todos los términos referidos al alma y al conocimiento, siendo reflejo de la complejidad que constituye la conformación misma de la realidad, en tanto que ésta se da como manifestación dinámica del principio divino. Desde esta dinamicidad ontológica hemos de comprender el dinamismo en la significación de los términos que quedan ubicados en el campo semántico de lo intelectivo. Uno de los textos que ha de darnos una pista en este sentido se encuentra en De Mysteriis 1.7.20:

El intelecto (Noṽ $\varsigma$, pues, jefe y rey de los seres, y el arte demiúrgico del universo están siempre del mismo modo presentes en los dioses, de un modo perfecto, suficiente, sin

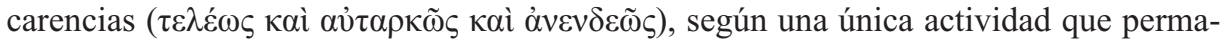
nece firme en sí misma de forma pura, mientras que el alma participa de un intelecto

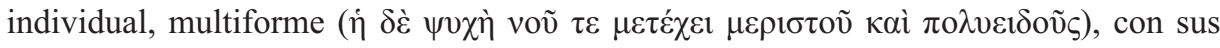


ojos en el gobierno del universo, y ella misma se cuida de los seres inanimados, tomando unas veces una forma y otras otra. 14

En la escala ontológica que constituye la realidad, el principio originario se expresa de modo gradual hasta la conformación misma de las formas sensibles. En este proceso creativo, el alma ocupa un lugar mediador entre las causas primordiales y las formas de los seres sensibles. De alguna manera, ella particulariza los principios causales permitiendo la recepción de estas causas al nivel de la sensibilidad. El alma da lo que recibe, proporcionándolo a los seres sensibles ${ }^{15}$. De este modo, el logos propio del alma queda conformado por la potencia del intelecto divino, constituyéndose en un despliegue de lo inteligible. Las razones de todas las cosas se dan, así, en el alma como una expresión de los principios inteligibles. En este sentido, el logos del alma puede ser concebido como un intelecto particular o como un reflejo particularizador del intelecto.

En la cualidad de este intelecto particular del alma se encuentra la clave que venimos buscando. El logos propio del alma acontece según una doble vertiente: una que podríamos denominar ontológica y otra propiamente lógica. La primera de ellas, antecede al razonamiento mismo y a la deliberación, es un puro reflejo de lo inteligible en las formas de todos los seres sensibles. Se trata de la capacidad creativa del alma en conexión con el intelecto divino. Para este logos intelectivo contemplar las formas inteligibles supone simultáneamente un desplegarlas en las razones de todas las cosas. La segunda vertiente en la que se despliega el logos del alma es la propiamente lógico-predicativa. Ésta se da en el lenguaje como un reflejo, a su vez, de la sabiduría intelectiva ínsita en el alma. En este sentido, leemos en Protréptico 19.19: "La divinidad imprimió en él <el hombre> el sistema de la razón plena, en el cual están contenidas todas las ideas de los seres y los significados de

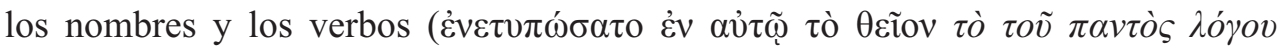

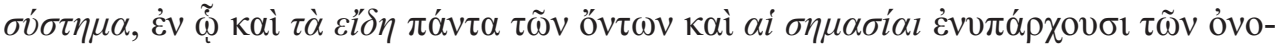

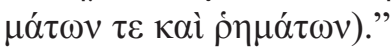

Tras esta afirmación se halla una concepción del lenguaje en profunda articulación con la conformación de lo real, a través de las ideas que el alma proporciona a

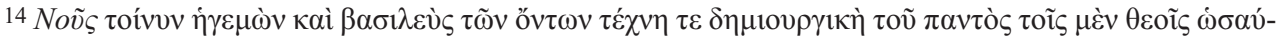

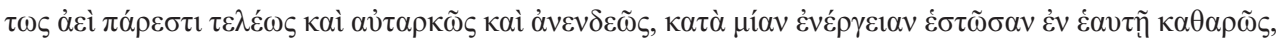

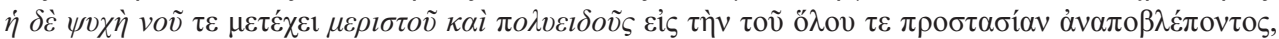

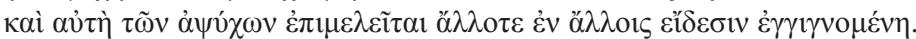

15 Cf. Myst. 1.5.69: "La división en la multiplicidad, la potencia de darse a otros y la recepción a partir de otros, en sí, del límite, la capacidad en el reparto de las cosas particulares como para complementarlas bien, la participación en un movimiento primordial y vivificante, la comunidad con todo lo

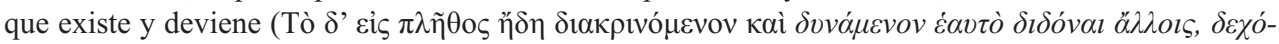

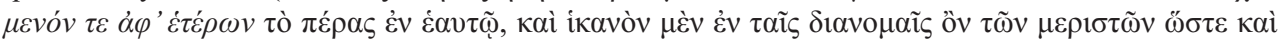

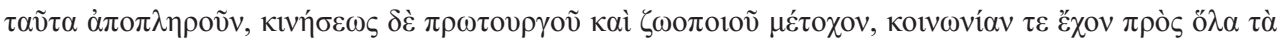

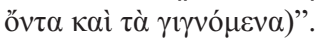


los seres como la estructura misma de su realidad. El lenguaje despliega su significatividad al nivel de cada una de las potencias del alma, hasta el nivel del despliegue en el ámbito fenoménico, el ámbito de la multiplicidad y del devenir, donde todo conocimiento conlleva de por sí la oposición que supone la referencia externa de un sujeto a una multiplicidad de objetos.

Esta disposición también es un despliegue del logos del alma, de su capacidad particularizadora, que va hasta los confines mismos de lo fenoménico. Esta vertiente lógica se mueve a un nivel inferior al de la contemplación de las formas y es demarcada por Jámblico como propiamente humana, en la medida en que se despliega al nivel del hombre concreto en el devenir mismo de su existencia particular. El modo de conocimiento que corresponde a esta vertiente del logos del alma es expresado en De Mysteriis 1.3.3 con los términos "razonamiento y demostración

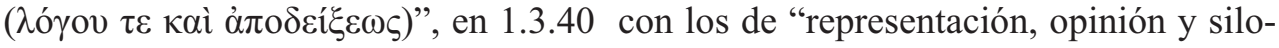
gismo (

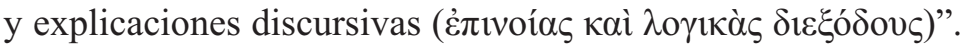

\section{Sobre los dos sentidos del término voepós: en relación a nosotros y en relación a lo divino}

Cuando Jámblico afirma en el texto de De Mysteriis 2.11.20-41, que venimos comentando en los epígrafes anteriores, que las obras inefables y los símbolos silenciosos "tampoco los llevamos a cabo con el pensar, pues en tal caso su actividad

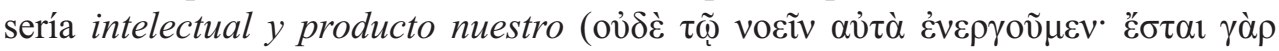

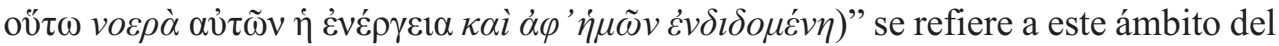
logos en su potencia lógico-predicativa. Éste puede ser referido como un cierto intelecto discursivo, en la medida en que él mismo constituye una de las vertientes del logos del alma, que, como tal, es un despliegue y una particularización del intelecto puro en la conformación de las razones de todas las cosas ${ }^{16}$. Los pensamientos

\footnotetext{
16 Esta misma distinción la encontramos en Plotino que habla de dos clases de intelecto, el discursivo y el que antecede a éste y lo posibilita. A este respecto, cf. En. V 1.10.12-13: voũ $\delta \dot{\varepsilon}$ ó $\mu \dot{\varepsilon} v$

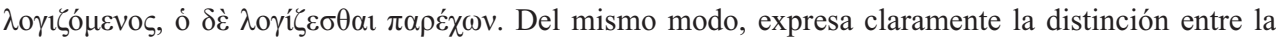
doble vertiente del logos del alma, la propiamente lógico-predicativa y la que se concibe como el despliegue mismo de lo inteligible en las razones conformadoras de todas las cosas. En este sentido, cf. $E n$. IV 3.18.2-13: "El raciocinio se hace presente en el alma en este mundo cuando se halla desconcertada, llena de preocupaciones y más debilitada.(...) La razón hay que entenderla como ha sido descrita porque si uno entiende por razón esa disposición que, dimanando perennemente del intelecto, está presente en las almas y que es una actividad estable y una especie de reflejo del intelecto cabe decir

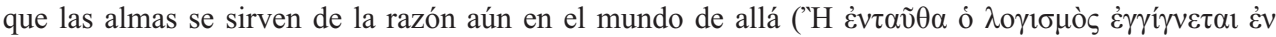

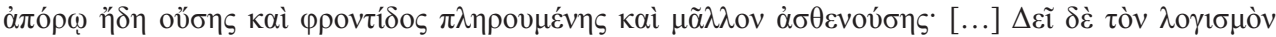

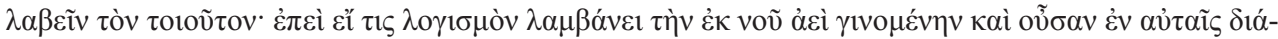

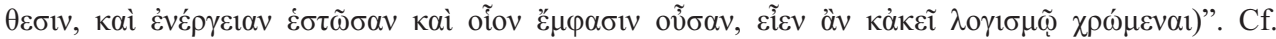


que proceden de este intelecto discursivo son propiamente "producto nuestro" y quedan asociados a nuestros modos propios de conocer. Son "nuestros" en la medida en que se mueven al nivel del ser humano concreto, que se ubica en el ámbito fenoménico de la multiplicidad y de la referencia externa. Este ámbito cognoscitivo debe ser trascendido en el saber intelectual y divino que no se da en la oposición y el devenir sino en grados crecientes de unidad que conducen al alma a la unión con el principio divino que la fundamenta.

De este modo, en el ámbito de lo intelectivo se da una complejidad semántica que se determina en función del lugar que ocupa el término en cada caso: voєpós, cuando viene ligado a "nosotros" queda referido al ámbito discursivo, del razonamiento, que implica oposición y despliegue temporal. De ahí que Jámblico diga en 2.11.20 que las obras inefables y los símbolos silenciosos "tampoco los llevaremos a cabo con el pensar pues entonces su actividad sería intelectual y producto nuestro

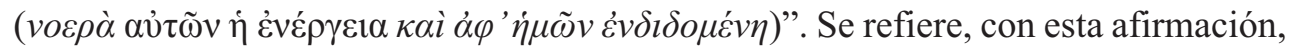
a que la actividad propia del símbolo trasciende el modo humano de conocimiento en tanto que propio de un ser concreto y particular que se mueve en el ámbito dual de lo fenoménico. Este modo de conocer, que queda demarcado como propiamente humano, debe ser trascendido en el modo de conocimiento "intelectual y divino" que porta el símbolo.

La elevación de los modos de comprensión del alma que facilita el símbolo procede de lo divino y promueve en ella grados cada vez mayores de apertura. En esta apertura de sí, el alma se conoce a sí misma como siendo una con el principio divino que la fundamenta. De ahí que se dé un trascender paulatino de la dualidad y del tiempo. Ningún razonamiento es posible en el lugar de la unión en el alma, los utillajes básicos de toda argumentación han sido trascendidos en una contemplación donde desaparece la oposición misma entre contemplador y contemplado17.

Este modo de conocimiento, que se despliega en orden a la asimilación y el contacto con lo divino, en su carácter mediador, tiene una naturaleza "intelectual y divina". Tal es la significación que abraza el término voepós cuando viene vinculado a lo divino. Apunta, entonces, al modo de conocimiento que se da por semejanza y que evoca en el alma el lugar de la unión al principio divino. En este sentido, afirmaba Jámblico en De Mysteriis 7.4.11 que: "lo que hay que retener en los nombres es precisamente aquella huella, intelectual y divina, que constituye un símbolo de la

Asimismo, En. III 8.6.20-30, texto en el que se distingue la disposición contemplativa del alma unificada al logos inteligible y su enunciación discursiva, en tanto que lo mira como siendo distinta "lo que enuncia lo enuncia a causa de su propia deficiencia tratando de comprender lo que ya posee" dirá Plotino.

17 Jámblico se une a toda la tradición platónica en su caracterización del saber contemplativo como modo de conocer que trasciende los modos discursivos del razonamiento. Cf. Myst. 4.3.18. Numerosos son los lugares en la obra de Plotino donde se expresa esta concepción. Cf. entre ellos, En. IV 818 ss., En. III 86 19-40, En. V8 1040 y III 8615. 


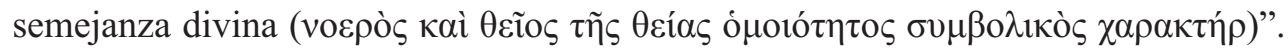

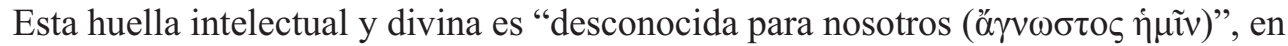
la medida en que trasciende los modos de conocimiento que se asocian al hombre como ser concreto que se relaciona con otros seres desde el ámbito fenoménico ${ }^{18}$.

De este modo, teniendo en cuenta el carácter dinámico del léxico referido al conocimiento intelectivo, es importante señalar que la oposición trazada en $D e$ Mysteriis 2.11.20-41 no es, como a primera vista pudiera parecer, entre el conocimiento intelectual en términos genéricos y el conocimiento simbólico, sino entre un modo de conocimiento divino y un conocimiento que sería "producto nuestro". Es en la estructura de esta relación fundamental entre lo divino y lo humano en la que debe ser ubicado el texto. Así como debe ubicarse en ella el dinamismo que guarda en su significación el término voepòৎ dependiendo de si se conjuga con lo divino o con lo humano. Conjugado el término con lo divino, apunta al modo mismo en que se despliega el conocimiento simbólico. Por el contrario, conjugado con lo humano, apela a los modos de conocimiento que deben ser trascendidos en la actividad del conocimiento simbólico, por desplegarse ésta desde la semejanza divina más allá de los modos de oposición que se dan en el razonamiento ${ }^{19}$.

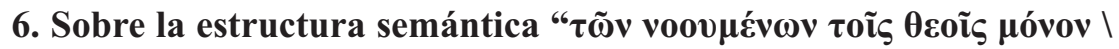

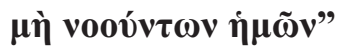

Este contraste fundamental entre el modo divino de conocimiento y el modo humano, que ha de ilustrarse insistentemente a lo largo de este texto de De Mysteriis 2.11.20-41, viene demarcado bajo la forma siguiente en las líneas 22-27:

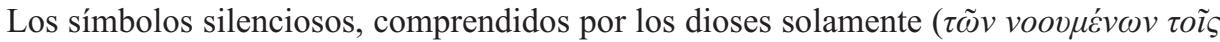

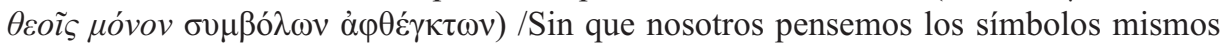

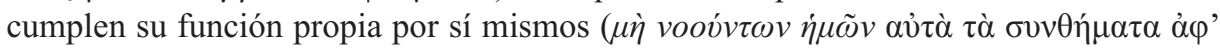

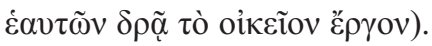

\footnotetext{
18 Para comprender correctamente la significación de esta afirmación hemos de tomar en cuenta que el término "nosotros" viene a referir precisamente el ámbito propiamente humano, del hombre como ser concreto. Sin embargo, esto no implica, en ningún caso, que el hombre no pueda acceder a lo divino y que, en última instancia, quede huérfano de todo saber acerca de lo divino. Se trata de ubicar el modo en que se da este conocimiento para el hombre, el modo concreto a través del cual el hombre puede acceder a lo divino. Con este fin práctico se indaga acerca de la naturaleza de lo divino y de lo humano, buscando en el hombre, precisamente, ese elemento divino que, constituyéndole en lo más profundo de su esencia, lo trasciende en tanto ser parcial que se mueve en el ámbito fenoménico junto con otros entes. Se trata de percibir el mundo desde la universalidad integradora del principio divino, esta contemplación inteligible se da más allá del hombre fenoménico, atendiendo a niveles de comprensión que se hallan en el núcleo divino que constituye a lo humano en su telos más íntimo.

19 Cf. Myst. toda la sección 3 del libro 1.
} 
El léxico referido a lo intelectivo queda aquí delimitado en su significación por la referencia al modo de conocer que se da en el ámbito de lo humano o en el ámbito de lo divino. Los símbolos silenciosos, cuya potencia se lleva a término en el trascender la actividad discursiva, son comprendidos por lo divino mismo. El adjetivo $\dot{\alpha} \varphi \theta \dot{\varepsilon} \gamma \kappa \tau$ ○ símbolo. El silencio al que apela este término se da en el trascender todo decir humano, en tanto decir que queda necesariamente articulado a partir de la oposición y el devenir, como su condición misma de posibilidad 20 . El modo humano de conocimiento debe ser trascendido para que sea posible el acceso a un conocimiento que, dándose por semejanza, está más allá de toda oposición 21 .

La necesidad de trascender el modo humano de conocimiento para acceder a la naturaleza propia del saber que porta el símbolo, que queda asociada a lo divino, se constituye, así, en el eje vertebrador del texto que nos ocupa. El contraste $\tau \tilde{\omega} v v o o v-$

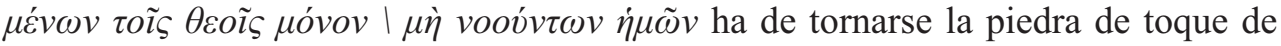
comprensión del estatuto que se atribuye al conocimiento simbólico en todo el pasaje de De Mysteriis 2.11.20-41. Se trata de incidir en la naturaleza divina de lo simbólico que trasciende, en su potencia misma, los modos humanos de conocimiento. No es, pues, el carácter no intelectivo del símbolo lo que se está señalando de modo genérico, sino el carácter trascendente del símbolo en relación a los modos discursivos de conocimiento.

De este modo, el sentido mismo del conocimiento simbólico queda delimitado en la complejidad semántica del léxico referido a lo intelectivo. Se trata de atender al modo de comprensión propio de los dioses, aquel que se da por semejanza, más allá de toda oposición, trascendiendo el modo de comprensión propio de los hombres, en tanto envueltos en el mundo de la multiplicidad y el devenir: La dualidad y la referencia externa que requiere necesariamente el carácter discursivo del razonamiento humano se ve, en última instancia, trascendida por el carácter unitivo del símbolo.

\footnotetext{
${ }^{20}$ En este sentido, Jámblico afirma en Myst. 8.3.7 que: "el primer inteligible es venerado sólo en silencio ( de acercamiento a lo divino, es una constante en el pensamiento neoplatónico. Cf. entre otros, Plotino, En. V 1 6, 8-11.

21 Esta es también una constante en el pensamiento de Plotino: el conocimiento intelectivo es aquel que se cumple en la semejanza a lo divino, trascendiendo toda oposición y la posibilidad de toda referencia externa, a partir de la cual se desarrolla el modo de conocimiento discursivo. Cf. entre otros pasajes, En. IV 81 5-9: "Unimismado con la divinidad y establecido en ella, ejercito aquella forma de actividad y me sitúo por encima de todo el resto de lo inteligible. Pero cuando luego, tras esa estancia en la región divina, descendiendo del intelecto al raciocinio, me pregunto perplejo cómo es posible

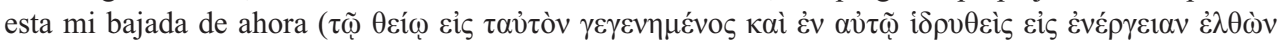

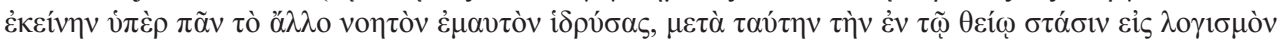

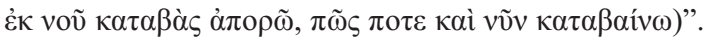


La estructura semántica que se forja en la relación entre lo humano y lo divino es una de las más determinantes para nuestro estudio por encontrarse a la base no sólo del pasaje de De Mysteriis 2.11.20 que venimos analizando, sino de prácticamente todas las nociones fundamentales de la filosofía de Jámblico. La comprensión de la cartografía epistémica, así como el estatuto intelectivo del conocimiento simbólico se hallan articulados de modo inmanente en esta estructura fundamental. La noción misma de filosofía depende de ella, así como lo que hemos de entender por teoría y práctica en el ámbito epistémico. La psique del hombre y su mismo fundamento queda enmarcada en la relación entre lo humano y lo divino. Esta relación establece, en su dinamismo, la compleja constitución que atraviesa la comprensión misma del hombre y sus modos de conocer, que derivan de esta constitución de modo radical.

Lo primero que hemos de tomar en cuenta, de cara a comprender la naturaleza de esta relación, es que entre lo humano y lo divino no hay una simple oposición que se dé desde la exterioridad. La conexión que vincula al hombre y a lo divino no puede comprenderse concibiéndolos como entes que se relacionaran el uno con el otro, como pudieran hacerlo dos seres particulares desde el ámbito fenoménico. Lo divino constituye a lo humano en el fundamento mismo de su esencia, allí donde ésta se trasciende a sí misma en una apertura receptiva hacia aquello que conforma su raíz. De otro lado, lo humano como tal no es en absoluto ajeno a lo divino sino que su propia particularidad y su esencia misma se forja en la potencia creativa de este principio originario 22 . En este sentido, la relación que se establece entre lo humano y lo divino es, asimismo, dinámica. Una concepción que relegara a estos dos términos a una relación estática, no articulada de modo inmanente, no daría cuenta de la estructura ontológica misma que atraviesa lo real en cada uno de sus niveles.

Lo divino forma parte de la estructura creativa misma de lo real, no hay una diferenciación dual entre lo divino y la realidad, como tampoco la hay entre lo divino y lo humano. Numerosos son los lugares de De Mysteriis donde se insiste en este carácter unitivo, a la vez que dinámico, de la realidad ${ }^{23}$. Desde esta comprensión debe entenderse el vínculo entre el hombre y lo divino. Éste trasciende las categorías de objeto y sujeto para insertarse en un modo complejo de articulación que no puede ser significado desde la relación que dos sujetos pudieran tener entre sí.

22 Cf. Myst. 1.8.51-57.

${ }^{23}$ Cf. Ib. 1.5.43 ss. y 1.6.17 ss. El núcleo mismo de toda reflexión en torno a la imagen y el símbolo será siempre esta paradoja consustancial a la conformación ontológica de lo real: El principio originario divino, siendo unitario, da de sí la conformación y la posibilidad misma de la multiplicidad. El carácter concreto de cada ser permanece en la unidad misma del principio divino, que lo constituye como su mismo fundamento en la concreción única e irrepetible de cada cosa particular. Esta condición hace que cada ser, en su estructura misma, se articule dinámicamente, de modo que su carácter sensible encuentra su fundamento en la naturaleza inteligible, que permanece en la unicidad del principio divino como fuente constitutiva de toda realidad. 
De este modo, cuando se apunta a un modo humano y un modo divino de conocimiento no se está delimitando un modo de conocer que sería ajeno al hombre, al que éste no podría acceder en ningún caso. No se trata de que el símbolo instaure un modo de conocimiento que corresponde a los dioses en tanto entidades, dejando fuera al hombre como un ente extraño a este modo de comprensión. Cuando se habla del modo humano y del modo divino de conocimiento se introduce un dinamismo epistémico que atañe al hombre mismo en su constitución esencial. El alma humana como tal hunde sus raíces en lo divino. La dinámica que se establece entre lo divino y lo humano es interna a la constitución del alma humana. Es el alma misma del hombre la que se relaciona con lo real desde los modos discursivos de conocimiento que son "propiamente humanos" o desde la apertura al principio originario mismo que constituye la realidad como un conocimiento "propiamente divino".

\section{Conclusión}

La compresión de las afirmaciones que lleva a cabo Jámblico respecto de la naturaleza del símbolo requiere un estudio previo de la significación de los términos que le están asociados, como el de voepóc. Esta significación no está delimitada de forma rígida, sino que se acompasa con la propia complejidad del marco teórico general que perfila en su obra. Es fundamental tener esto en cuenta para no proyectar sobre su comprensión de lo simbólico un marco teórico ajeno. La dicotomía intelectual/anti-intelectual no da cuenta, como hemos visto, de la profundidad de la noción del símbolo. Éste no es considerado por Jámblico como un elemento irracional que abriese una nueva vía de unión a lo divino, contrapuesta a la que propone Plotino.

Se hace necesario acompasar la lectura de los textos con un marco teórico capaz de dar cuenta de ellos, desde la complejidad que los constituye; un marco capaz de abrir su estudio y su vinculación con nociones fundamentales de la filosofía de Plotino. El símbolo guarda en sí una naturaleza intelectual, atiende al modo de conocimiento propio del intelecto, a su cualidad contemplativa. Este modo de conocimiento es ya divino en toda la tradición platónica y, sin embargo, pertenece al hombre en su esencia misma. El estatuto propio del intelecto y de su modo de conocimiento es una de las cuestiones más complejas del pensamiento griego, un ámbito que bordea siempre la paradoja y que supone un reto para la mentalidad del hombre contemporáneo. En Ética a Nicómaco 1177.b.20-1178.a.10, Aristóteles expone la cuestión de manera magistral:

Tal vida, sin embargo, sería superior a la de un hombre, pues el hombre viviría de esta

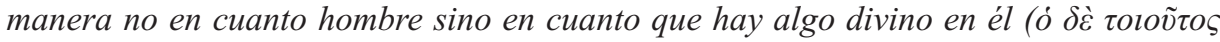

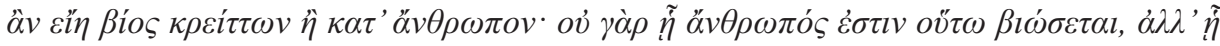




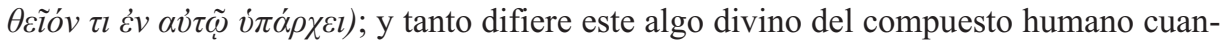
to su actividad de la que se da según las otras virtudes. Si, pues, el intelecto es divino respecto al hombre, también la vida según él será divina respecto a la vida humana. Pero no hemos de seguir los consejos de algunos que dicen que, siendo hombres, debemos pensar sólo humanamente $\mathrm{y}$, siendo mortales, ocuparnos sólo de las cosas mortales, sino que debemos, en la medida de lo posible, inmortalizarnos y hacer todo esfuerzo para vivir de acuerdo con lo más excelente que hay en nosotros: pues aún cuando esta parte sea pequeña en volumen, sobrepasa a todas las otras en dignidad y poder. Y pare-

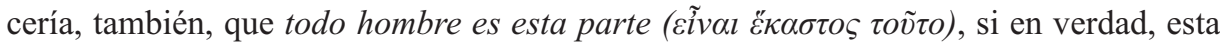
es la parte rectora y la mejor; por consiguiente sería absurdo que un hombre no eligie-

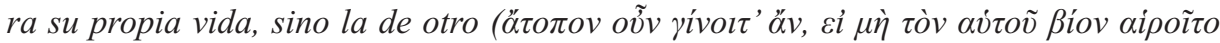
$\dot{\alpha} \lambda \lambda \dot{\alpha} \tau \imath v o \varsigma \ddot{\alpha} \lambda \lambda o v)$.

La vida conforme al intelecto, esa vida que es superior a la de un hombre es precisamente su propia vida. Tomás Calvo se refiere lúcidamente a este texto afirmando que: "Aristóteles no habla metafóricamente cuando afirma [...] que el entendimiento es algo divino o lo más divino que hay en nosotros y cuando añade que una vida dedicada exclusiva y plenamente a la contemplación «sería superior a la del hombre: en efecto, viviría así no en tanto que es hombre, sino en tanto que algo divino hay en él» (ib.1177 b 27-29) La contraposición establecida en estas últimas palabras (en tanto que hombre/ en tanto que hay en él algo divino) muestra que Aristóteles es consciente de hallarse en una encrucijada" 24 . En el espacio de esta encrucijada vienen a habitar un gran número de cuestiones fundamentales para la filosofía griega, la cuestión de lo simbólico que hemos tratado en estas páginas es una de ellas.

La complejidad del conocimiento propio del intelecto debe ser tomada en cuenta para comprender profundamente el símbolo y su carácter epistémico. Lo simbólico no apela a un ámbito sobrenatural que instaurara un espacio irracional, vinculado a la superstición; no viene a suplir la debilidad del alma humana que no podría ya alcanzar lo divino por sus propias fuerzas. En toda la tradición neoplatónica la fuerza que vincula al hombre con el principio fundamental de la realidad es ya divina. La novedad que Jámblico introduce respecto del pensamiento de Plotino no se deja delimitar desde estos marcos de lectura. Otro es el lugar del símbolo en el pensamiento de Jámblico y la novedad indudable que introduce. Ésta no puede ser comprendida sin tomar en cuenta el carácter intelectual de lo simbólico que vincula esta noción con la función epistémica de la belleza en la filosofía de Plotino. Muy lejos nos llevaría esta cuestión, baste por el momento con apuntar que símbolo y belleza estarán vinculados estrechamente en el pensamiento de Jámblico. Éste tomará el poder mediador de la belleza en la tradición platónica, su carácter propio, su fun-

24 Cf. Calvo Martínez T. Aristóteles y el aristotelismo, Madrid: Akal 1996, p. 42. 
ción, para desplegar una exégesis sin precedentes de lo simbólico que ha de influir de modo perdurable en el pensamiento posterior.

\section{Referencias bibliográficas}

\section{Autores antiguos}

Aristóteles. Ética Nicomáquea y Ética Eudemia, introd., de Lledó I., trad. y notas de Pallí J., Madrid: Gredos, 1998.

JÁmblico. Jamblique. Les Mystères d'Égypte, ed. y trad. Des Places E., París : Les Belles Lettres, 1966. (Trad. castellana de Ramos Jurado E., Madrid: Gredos, 1997).

JÁmblico. Jamblique, Protreptique, ed. y trad. E. Des Places, París : Les Belles Lettres, 1986. (Trad. castellana, Pierago M., Madrid: Gredos, 2003).

Plotino. Enéadas I-VI, 3 vols. Introd., trad. y notas de J. Igal, Madrid: Gredos, 1982-1998.

\section{Estudios modernos}

Brisson L. Orphée, Pythagore et Platon. Le mythe qui établit cette lignée, en Metaphysic und Religion. Leipzig, 2002.

Calvo Martínez T. "Léxico y filosofía en los presocráticos", en Logos. Anales del Seminario de Metafisica, Vol. VI, 1971.

Calvo Martínez T. Aristóteles y el aristotelismo, Madrid: Akal 1996.

Clarke E. C. Iamblichus'De Mysteriis: A manifiesto of the miraculous, Aldershot: Alsgate, 2001.

DalsgaArD L.B. Jamblique de Chalcis, exégète et philosophe, Aarhus: Universitetforlaget, 1972.

Dodds E. R. The greeks and the irracional, Berkeley: Univ. of California Press, 1973 (Trad. española de Araujo M.: Los griegos y lo irracional, Madrid: Alianza, 1981, p. 270).

Hermoso FÉlix M.J. "Saber y razón en el Neoplatonismo: hacia una nueva comprensión de la filosofía de Jámblico", en Anales del Seminario de historia de la Filosofía, Vol. 29, nº1, 2012, pp. 27-44.

LEwY H. Chaldean Oracles and theurgy. París, 1978.

SAFFREY H. D. La théurgie chez les néoplatoniciens, en Recherches sur le Néoplatonisme après Plotin. París, 1990.

SAGET C. "La théurgie, nouvelle figure de l'ergon dans la vie philosophique", en The divine Iamblichus, philosopher and man of Gods. Henry I. Blumenthal \& E. Gillian Clark ed. Bristol: Bristol Classical Press, 1993. 
Uzdavinys A. Philosophy and Theurgy in Late Antiquity, USA: Sophia Perennis, 2010.

Van Liefferinge C. La Thèurgie: Des Oracles Chäldaiques à Proclus, Liège : Kernos, 1999.

María Jesús Hermoso Félix

Universidad de Valladolid

Facultad de Filosofía

mjhermosofelix@yahoo.es 